\title{
Nutritional Status and Effect of Maternal Employment among Children Aged 6-59 Months in Wolayta Sodo Town, Southern Ethiopia: A Cross-sectional Study
}

\author{
Hiwot Eshete ${ }^{1}$, Yewelsew Abebe ${ }^{2}$, Eskindir Loha ${ }^{2}$, Teklemichael Gebru ${ }^{3 *}$, \\ Tesfalem Tesheme ${ }^{1}$
}

OPEN ACCESS

Citation: Hiwot Eshete, Yewelsew Abebe, Eskindir Loha, Teklemichael Gebru, Tesfalem Tesheme. Nutritional Status and Effect of Maternal Employment among Children Aged 6-59 Months in Wolayta Sodo Town, Southern Ethiopia: A Crosssectional Study. Ethiop J Health Sci 2017;27(1):155. doi: http://dx.doi.org/10.4314/ejhs.v27i2.8

Received: October 19, 2016

Accepted: November 24, 2016

Published: March 1, 2017

Copyright: () 2015 Hiwot E, et al. This

is an open access article distributed under the terms of the Creative Commons Attribution License, which permits unrestricted use, distribution, and reproduction in any medium, provided the original author and source are credited. Funding:Hawassa University

Competing Interests: The authors declare that this manuscript was approved by all authors in its form and that no competing interest exists.

Affiliation and Correspondence: ${ }^{1}$ Department of Public Health,

Hadassah Health Science College, Hadassah, Ethiopia

${ }^{2}$ College of Health Science, Hawassa University, Hawassa, Ethiopia

${ }^{3}$ Department of Public Health,

WolkiteUnivesity, Wolkite, Ethiopia

"Email:

teklemichaelgebru@gmail.com

\section{ABSTRACT}

BACKGROUND: Childhood malnutrition remains common in many parts of the world; the magnitude of worldwide stunting, underweight and wasting in children under five years of age were $24.7 \%, 15.1 \%$ and $7.8 \%$, respectively. More than 150 million children under the age of five years in the developing world are malnourished. Ethiopia is one of the countries in sub-Saharan Africa with the highest rates of malnutrition. In Ethiopia, $44.4 \%$ and $9.7 \%$ of children under-five years old were stunted and wasted, respectively. This study was aimed to assess nutritional status and effect of maternal employment among children aged 6-59 months.

METHODS: A cross-sectional study was conducted in Wolayta Sodo Town, Southern Ethiopia. Socio-demographic characteristics, child feeding and healthcare seeking practice of mothers, and child's anthropometric status were assessed. Probability proportional to size sampling approach was used to select a sample of 316 mothers having children aged 6-59 months. The study was ethically approved by Institutional Review Board of Health Science College, Hawasa University.

RESULT: The overall result revealed that the prevalence of stunting was $22.2 \%$, of which $21.8 \%$ and $22.6 \%$ were in children of employed and unemployed mothers, respectively. Low-weight-for age was $10.8 \%$ for children of employed mothers and $13.4 \%$ for children of unemployed mothers. Wasting was $8.8 \%$ and $10.8 \%$ for children of employed and unemployed mothers, respectively. There was no statistically significant association between maternal employment and nutritional status of their children. However, chronic malnutrition (stunting) was influenced by being educated mother (OR: 0.37) child age group of 24-59 months (OR: 0.36) and households' fifth wealth quintile (OR: 0.28).

CONCLUSION: Low prevalence of stunting was observed. Stunting is a public health concern in the study area. Furthermore, stunting is significantly influenced by mothers' education, household wealth and child age. However, maternal employment was not statistically associated with child nutritional status. Thus, nutritional intervention initiatives should focus on improving household food security, maternal education and agricultural diversification.

KEYWORDS: Childhood Nutrition, Maternal employment, Southern Ethiopia

DOI: http://dx.doi.org/10.4314/ejhs.v27i2.8 


\section{INTRODUCTION}

Childhood malnutrition remains common in many parts of the world; it is the underlying cause of death in an estimated $45 \%$ of all deaths among children under five years old (1). The magnitude of worldwide stunting, underweight and wasting in children under five years of age were $24.7 \%, 15.1 \%$ and $7.8 \%$, respectively (2). More than 150 million $(39.9 \%)$ children under the age of five years in African countries are malnourished (3). Ethiopia is one of the countries in subSaharan Africa with the highest rate of malnutrition. According to the recent EDHS report, $44.4 \%, 9.7 \%$ and $38 \%$ of children under five years old were stunted, wasted and underweight, respectively (4).

The causes of malnutrition are classified as immediate, underlying and basic. The immediate or direct causes are inadequate or inappropriate dietary-intake and infectious diseases, whereas insufficient access to food, childcare, water supply and environmental sanitation are underlying causes. Political, cultural, religious, economic and social systems including women's status in the society are considered as basic causes for malnutrition(5).

Women's employment increases household income with consequent benefit to increase women's status and power. This may bolster a woman's preference to spend her earnings on health and nutrition. In effect women without control over their income and decision-making authority within the household economic power have an ability to take actions on their babies' nutritional status (6) However, it may also have negative effects on the nutritional status of children as it decrease mothers' time spent for their children's caring, feeding and breastfeeding and increases care giving by

Therefore, this study examined the association of mothers' employment status on other individuals than by their mothers (7). On the other hand, children's nutritional status may not associate with maternal employment. nutrition and health status of children. We believed that the finding of the study would be helpful in producing applicable recommendations that could show more areas of effective interventional programs for both government \& non-government organizations for continued improvement of child health and nutritional status.

\section{METHODS}

A community based cross-sectional study was conducted in January 2014 at Wolayta Sodo Town, located $380 \mathrm{~km}$ away from the capital city Addis Ababa to South in South Nations Nationality Peoples' Region(SNNPR). The town lies between $4.43^{\circ}-8.58^{\circ}$ North latitude and $34.88^{\circ}-39.14^{\circ}$ East longitude. It has a total population of 126,759 : $67,331(53.11 \%)$ males and 59,428(46.88\%) females.

In this study, all households that had at least one child aged 6 to 59 months in the town were the source population, whereas households who resided in selected Kebels were the population. Furthermore, in this study, mothers who had regular jobs with a specified salary respective to the index child's age at the data collection time were considered as employed mothers. However, mothers who were irregularly employed after giving the index child birth were excluded from the study.

Sample size was calculated using single population proportion formula by taking $32 \%$ prevalence of stunting in children (4), 95\% confidence interval (CI), and relative precision $5 \%$ and expected response rate 90\%. Accordingly, the calculated optimal sample size was 367 households that had at least one child of 6 to 59 months old. However, the source population is less than 10,000 i.e. 2,274 and the finite population correction is greater than 5\%. Thus, it needs sample size correction which gives 316 households that had at least one child aged 6 to 59 months were included in the study.

Probability proportional to size sampling procedure was employed to select the study participants. First, we listed all Kebeles existing in Wolayta Town with their target tion size prepared from the preliminary survey. Following we computed the

DOI: http://dx.doi.org/10.4314/ejhs.v27i2.8 
cumulative frequency and sampling interval by dividing in to $30 \%$ of the Kebeles (three) were 2,274 and 758, respectively. Finally, randomly, we chose a number between 1 and 758 to determine the first cluster sample and followed the interval until the required three kebele were identified, and finally simple random sampling was applied to select the study units from each kebele. However, if more than one child aged 6 to 59 months were found in the sampled single household, lottery method was applied to select the index child.

An adapted questionnaire was used to collect the data by six trained diploma holding nurse data collectors (4). Anthropometric measurement of children were made using electronic weight scale (Seca 770) wearing light shirt of known weight, and stadio-meter for length and height for under-two children, and for 24-59 months children without shoes, respectively. Weights and lengths/heights were taken to the nearest $0.1 \mathrm{~kg}$ and $1-\mathrm{cm}$, respectively. Furthermore, in addition to instrument calibration, scale indicators were checked against zero reading after weighing every child.

To enhance instrument reliability, the adapted questionnaire was translated into the local language, Amharic, and back translated into English by another language expert. Moreover, the instrument was pre-tested on $5 \%$ of the actual sample size and necessary corrections were made accordingly. Threeday training was given to data collectors and supervisors before the data collection. The overall data collection process was monitored on a daily base by BSc holding supervisors and investigators. An Epi-data 3.1 statistical package was used for data entry, whereas data processing and analysis was made using SPSS version 20.0 .

Anthropometric indexes, Z-scores for Height-for-age (WAZ), weight-for-Height (WHZ) and MUAC-for-age were computed from the WHO 2006 multi-center growth reference data using the computer program WHO Anthro 2007 (8). Variables in the binary analysis found at $p$-value $\leq 0.10$ were further considered into the final model multiple logistic regression to evade unstable estimate (9). Finally, backward stepwise logistic regression analysis was applied to describe the practical associated factors of childhood malnutrition. A point estimates of Odds ratio (OR) with $95 \%$ confidence interval (CI) was computed to assess the strength of association between the independent variables and the outcome childhood malnutrition. For all statistical significance tests, $\mathrm{p}$-value $<0.05$ was used as a cut-off point.

The study was ethically approved by Hawassa University Ethical Review Board, and support letter was obtained from Wolayta Hone Health Department. A written informed consent from the next of kin, caretakers or guardians on behalf of the minors/children enrolled in the study was obtained before each interview and measurement. Sick and severely malnourished children were referred to health facilities, and health/nutritional advice was given to parents. Moreover, confidentiality of the data was assured. RESULTS

Socio-demographic characteristics of the study population: Three hundred sixteen mothers having children age 6-59 months were planned to be included in this study. Out of these, 315 were enrolled in the data collection which gives a response rate of 99.6\%. Among the study participants, $195(61.9 \%)$ mothers with children aged 6-59 months were unemployed, while $120(38.1 \%)$ mothers with children age 6-59 months were employed.

The majority, 289(91.7\%), of the mothers were married. However, more of the employed mothers were divorced $8(2.5 \%)$ compared to their counterpart were null. Regarding religion, Protestant Christian was slightly more than half, constituting $185(58.7 \%)$ followed by Orthodox. The mean ages of mothers and children were 26.6 years and 29.5 months, respectively. On the other hand the mean family size of the study participant was 5.09. The majority of mothers, $264(83.8 \%)$, were literate, but only $97(30.8 \%)$ of them were employed. Majority of the household's wealth was third level (Table 1). 
Table 1: Socio-demographic characteristics of study participants $(n=315)$, Wolayta Sodo Town, January 2014

\begin{tabular}{|c|c|c|}
\hline Variables & $\begin{array}{r}\text { Employed } \\
n(\%) \\
\end{array}$ & $\begin{array}{r}\text { Unemployed } \\
\text { n (\%) } \\
\end{array}$ \\
\hline \multicolumn{3}{|l|}{ Mean(SD) } \\
\hline Child age in month & $30.73 \pm 14.8$ & $27.4 \pm 14.2$ \\
\hline Maternal age & $27 \pm 5.23$ & $26.2 \pm 5.34$ \\
\hline Family size & $5.17 \pm 1.88$ & $5.01 \pm 1.76$ \\
\hline \multicolumn{3}{|l|}{ Marital status } \\
\hline Married & $102(32.4)$ & $189(59.4)$ \\
\hline Unmarried & $1(0.3)$ & $2(0.6)$ \\
\hline Divorced & $8(2.5)$ & $0(0)$ \\
\hline Widowed & $9(2.9)$ & $6(1.9)$ \\
\hline \multicolumn{3}{|l|}{ Education } \\
\hline Literate & $97(30.8)$ & $167(53.0)$ \\
\hline Not read \& write & $23(7.3)$ & $28(8.9)$ \\
\hline \multicolumn{3}{|l|}{ Religion } \\
\hline Protestant & $72(22.8)$ & $113(35.9)$ \\
\hline Orthodox & $43(13.7)$ & $75(23.8)$ \\
\hline Muslim & $6(1.9)$ & $3(1.0)$ \\
\hline Catholic & $2(0.6)$ & $1(0.3)$ \\
\hline \multicolumn{3}{|l|}{ Under five children size } \\
\hline One & $102(32.4)$ & $166(52.7)$ \\
\hline Two & $16(5.1)$ & $27(8.6)$ \\
\hline Three & $2(0.6)$ & $2(0.6)$ \\
\hline \multicolumn{3}{|l|}{ Household wealth } \\
\hline First & $19(15.8)$ & $44(22.6)$ \\
\hline Second & $24(20.0)$ & $40(20.5)$ \\
\hline Third & $19(15.8)$ & $44(22.6)$ \\
\hline Fourth & $31(25.8)$ & $35(17.9)$ \\
\hline Fifth & $27(22.5)$ & $32(16.4)$ \\
\hline
\end{tabular}

Child feeding pattern and health seeking behaviors: About $270(85.7 \%)$ of the respondents had breastfed their child3n, of which 109(90.8\%) were employed mothers. The rest introduced other food and/or fluids. Concerning the time of initiation of breastfeeding, the majority, 200(74.1\%), of the children were initiated at appropriate time (with in the $1^{\text {st }}$ hour after birth). Of these, $29.3 \%$ were children of employed mothers.

No mother reported that she had started additional food to her child immediately after birth. However, 180(66.7\%) of the mothers started complementary food to their children at the age of
6 months; of these, 67(37.2\%) were employed mothers. Fifty-seven (21.1\%) mothers started additional food to their children after 6 months of age. Of these, 21(19.3\%) mothers were employed, while $33(12.2 \%$ ) of them started additional food to the children before 6 months of age after birth.

Pertaining to mothers' knowledge about complementary feeding, about $298(94.6 \%)$ of the mothers explained the time for starting complementary feeding as 4-6 months of age, and 312(99 \%) explained as exclusive breast feeding should be given for up to 6 months.

The majority of the children, 291(92.4\%), had received immunization for common childhood

DOI: http://dx.doi.org/10.4314/ejhs.v27i2.8 
illnesses. Among the study participant mothers $48(87.3 \%)$ for fever, 54(67.6\%) for cough and 23 $(69.7 \%)$ for diarrheal childhood illness seeks advice or treatment from different public and private health facilities.

Concerning the delivery place, half $56(46.7 \%)$, of the employed mothers delivered at health institutions. The remaining gave birth at home assisted by Traditional Birth attendants (TBAs) and/or relatives.
According to the mothers' responses and records obtained from child vaccination cards, $93(47.7 \%)$ of the children of unemployed mothers and $45(37.5 \%)$ of the children of employed mothers were weighed at birth. Among children whose weights were measured, 5(3.6\%) were below 2500gms; of these $3(2.5 \%)$ and $2(1.03 \%)$ belonged to unemployed and employed mothers, respectively (Table 2 ).

Table 2: Child feeding practices and Health Seeking Behaviors of the respondents ( $\mathrm{n}=315)$, Wolayta Sodo Town, January 2014.

\begin{tabular}{|c|c|c|}
\hline Variables & $\begin{array}{r}\text { Employed } \\
\text { n (\%) }\end{array}$ & $\begin{array}{r}\text { Unemployed } \\
\text { n (\%) }\end{array}$ \\
\hline \multicolumn{3}{|l|}{ Initiation of breast feeding $(n=270)$} \\
\hline First hour & $79(29.3)$ & 121(44.8) \\
\hline Within 8 hours & $29(10.7)$ & $30(11.1)$ \\
\hline After 24 hours & $1(0.4)$ & $10(3.7)$ \\
\hline \multicolumn{3}{|c|}{ Initiation of complementary feeding $(n=270)$} \\
\hline At 6 month & $67(37.2)$ & $113(62.8)$ \\
\hline After 6 month & $21(36.8)$ & $36(63.2)$ \\
\hline Less than 6 month & $21(63.6)$ & $12(36.4)$ \\
\hline \multicolumn{3}{|l|}{ Seeking advice or treatment for sickness } \\
\hline Fever $(n=48)$ & 20(90.9) & $28(84.8)$ \\
\hline Cough $(n=54)$ & $25(69.4)$ & $29(65.9)$ \\
\hline Diarrhea $(n=23)$ & $8(61.5)$ & $15(75.0)$ \\
\hline \multicolumn{3}{|l|}{ Immunization } \\
\hline Yes & $108(90.0)$ & $183(93.8)$ \\
\hline No & $12(10.0)$ & $12(6.2)$ \\
\hline \multicolumn{3}{|l|}{ Place of delivery } \\
\hline Health institution & $56(46.7)$ & $106(54.4)$ \\
\hline Outside Health institution (home) & $64(53.3)$ & $89(44.6)$ \\
\hline \multicolumn{3}{|l|}{ Children weighed at birth } \\
\hline No & $75(62.5)$ & $102(52.3)$ \\
\hline Yes & $45(37.5)$ & $93(47.7)$ \\
\hline
\end{tabular}

Nutritional status description: Thirty-eight (12.1 $\%)$ of the children were underweight, of these, $10.8 \%$ from employed mothers and $13.4 \%$ from the counter parts. On the other hands $70(22.2 \%)$ were stunted of which $21.8 \%$ and $22.6 \%$ in children from employed and unemployed mothers, respectively. Thirty-one (9.8\%) of the children were wasted. Of these, $8.8 \%$ and $10.8 \%$ were children of employed and unemployed mothers, respectively. The mean $( \pm \mathrm{SD})$ weight-for-age, height-for-age and weight-for-height $\mathrm{Z}$ scores were, $2.85( \pm 0.42), 2.73( \pm 0.51)$ and $2.83( \pm 0.32)$, respectively (Table 3 ). 
Table 3: Anthropometric characteristics of children involved in the study $(n=315)$, Wolayta Sodo Town, January 2014.

\begin{tabular}{|c|c|c|}
\hline Variables & Frequency (n) & Percent (\%) \\
\hline \multicolumn{3}{|l|}{ Weight-for-age $Z$ Z score } \\
\hline Normal $(\geq-2$ SD $)$ & 277 & 87.9 \\
\hline Underweight $(<-2 \mathrm{SD})$ & 29 & 9.2 \\
\hline Severely underweight $(<-3 \mathrm{SD})$ & 9 & 2.9 \\
\hline \multicolumn{3}{|l|}{ Height-for-age $Z$ score } \\
\hline Normal ( $>-2$ SD) & 245 & 77.8 \\
\hline Stunted $(<-2 \mathrm{SD})$ & 58 & 18.4 \\
\hline Severely stunted(<-3SD) & 12 & 3.8 \\
\hline \multicolumn{3}{|l|}{ Weight -for-height $\mathrm{Z}$ score } \\
\hline Normal $(>-2 \mathrm{SD})$ & 284 & 90.2 \\
\hline Wasted $(<-2 \mathrm{SD})$ & 29 & 9.2 \\
\hline Severely wasted $(<-3 S D)$ & 2 & 0.6 \\
\hline \multicolumn{3}{|l|}{ MUAC- for-age Z score } \\
\hline Normal ( > -2SD) & 250 & 79.4 \\
\hline Wasted $(<-2 \mathrm{SD})$ & 57 & 18.1 \\
\hline Severely wasted $(<-3 \mathrm{SD})$ & 8 & 2.5 \\
\hline \multicolumn{3}{|c|}{$\begin{array}{ll}\text { Factors influencing the nutritional status of } & \text { illiterate mothers [OR: 0.37, 95\%CI: }(0.19,0.74)] \text {. } \\
\text { children: As shown in Table 4, stunting was } & \text { Also, children from the fifth wealth quintile } \\
\text { insignificantly associated with maternal } & \text { household and child age group 24-59 months were } \\
\text { employment and maternal age. However, stunting } & 70 \% \text { and } 64 \% \text { less likely to be stunted compared } \\
\text { appeared to be significantly influenced by } & \text { to lowest wealth quintile household and child age } \\
\text { maternal education, child age and household } & \text { group of 6-23 months [OR: 0.28, 95\%CI: }(0.10, \\
\text { wealth. Children of literate mothers were 63\% less } & 0.77)] \text { and [(OR :0.36, 95\%CI: (0.17, 0.77)], } \\
\text { likely to be stunted as compared to children of } & \text { respectively. }\end{array}$} \\
\hline
\end{tabular}

Table 4: Predictors of childhood malnutrition ( $\mathrm{n}=315)$, Wolayta Sodo Town, January 2014

\begin{tabular}{|c|c|c|c|c|}
\hline \multirow[t]{2}{*}{ Variables } & \multirow[t]{2}{*}{ Crude OR with $95 \%$ CI } & \multicolumn{3}{|c|}{ Adjusted OR with 95\% CI } \\
\hline & & Stunting & Wasting & Under weight \\
\hline \multicolumn{5}{|l|}{ Maternal employment } \\
\hline Unemployed & 1 & 1 & 1 & 1 \\
\hline Employed & $0.87(0.49,1.55)$ & $0.87(0.49,1.55)$ & $0.75(0.34,1.66)$ & $0.83(0.41,1.69)$ \\
\hline \multicolumn{5}{|l|}{ Education } \\
\hline Can't read \& write & 1 & 1 & 1 & 1 \\
\hline Literate & $0.45(0.24,0.86)$ & $0.37(0.19,0.74)^{*}$ & $0.53(0.15,1.80)$ & $0.48(0.22,1.07)$ \\
\hline \multicolumn{5}{|l|}{ Maternal age } \\
\hline $15-34$ & 1 & 1 & 1 & 1 \\
\hline $35-54$ & $1.58(0.92,2.72)$ & $1.58(0.92,2.72)$ & $0.53(0.25,1.11)$ & $0.54(0.27,1.08)$ \\
\hline \multicolumn{5}{|l|}{ Child age } \\
\hline $6-23$ & 1 & 1 & 1 & 1 \\
\hline $24-59$ & $0.39(0.82,1.02)$ & $0.36(0.17,0.77)^{*}$ & $1.97(0.45,8.64)$ & $0.42(0.18,1.01)$ \\
\hline \multicolumn{5}{|l|}{ Household Wealth } \\
\hline First & 1 & 1 & 1 & 1 \\
\hline Second & $0.39(0.41,1.11)$ & $0.38(0.13,1.09)$ & $0.79(0.17,3.69)$ & $0.56(0.23,1.82)$ \\
\hline Third & $0.35(0.13,0.98)$ & $0.32(0.12,0.93)$ & $0.37(0.09,1.49)$ & $0.65(0.20,2.11)$ \\
\hline Fourth & $0.34(0.12,0.93)$ & $0.35(0.12,1.10)$ & $0.43(0.11,1.74)$ & $0.74(0.22,2.47)$ \\
\hline Fifth & $0.28(0.10,0.77)$ & $0.28(0.10,0.77) *$ & $0.34(0.09,1.32)$ & $0.58(0.18,1.86)$ \\
\hline
\end{tabular}

$* \mathrm{P}<0.05$

DOI: http://dx.doi.org/10.4314/ejhs.v27i2.8 


\section{DISCUSSION}

The study found that about $38.1 \%$ of the respondents were employed in different governmental and non-governmental organizations. This is consistent with the national survey report $40 \%$ of urban women (10-12).

The overall result showed that the prevalence of malnutrition was $29.9 \%, 18.4 \%$ and $29.9 \%$ for underweight, stunting and wasting, respectively. However, the prevalence of underweight and stunting were lower than the reported prevalence in the national survey of SNNPR in which they were $34.7 \%$ and $51.6 \%$, respectively, while the prevalence of wasting was higher than the SNNPR report of $6.5 \%(12-14)$.

The study also showed that $90.8 \%$ and $82.6 \%$ of the children of employed and unemployed mothers, respectively, were breastfed. The percentages in both groups were lower than the national report of $96.6 \%(5,12,15,16)$. Regarding complementary feeding practice, the majority, $66.7 \%$ (62.7 unemployed and 37.2 employed), mothers was started complementary feeding for their children of 6 months of age. This result is higher than the study done in Addis Ababa in which it was $21.8 \%$ (13), but high percent of employed women was started complementary feeding as early as the recommended age compared with their unemployed counterparts.

This study revealed that the overall nutritional status of children of employed mothers showed insignificant difference from that of children of unemployed mothers. The same insignificant association was reported in Ethiopia. Likewise, another studies reported no significant association between stunting and employment status of mothers $(4,17)$. This may be explained due to similarity of caregiver during maternal leave for those employed mothers, and/or babies may get the same care by other individuals than by their mothers.

Maternal education proved to be the most important predictor of chronic malnutrition. The possible explanation could be that the knowledge and understanding of mothers have on child nutrition and feeding practices were likely to have a positive impact on their children nutritional status. Proper education of mothers, in addition to improving their children's feeding practices, will enable them to recognize signs of malnutrition and increase health care seeking behaviors. A similar finding was also reported in a study done in Bangladesh (11).

In this study, household wealth was significantly associated with chronic malnutrition (stunting) of children, and in this regard, the importance of the socio-economic status of a population in determining malnutrition was evident. Thus, the result suggests that household economy could be an important factor for the nutritional status of children. This finding was also consistent with a study done elsewhere (11, 12,18,19).

The prevalence of stunting was significantly higher $(22.2 \%)$ in the age group of 6-23 months compared with their older counterparts of 24-59 years of age $(10.8 \%)$. This supports the fact that there is the highest prevalence of stunting in the younger children than in older children (11). Overall, this study may be subjected to recall bias on exclusive breast-feeding, initiation of complementary feeding and initiation of breastfeeding.

In conclusion, the overall nutritional (anthropometric) status of children of employed mothers and unemployed mothers were compared. Nevertheless, the difference was not statistically significant. Overall, a high prevalence of stunting was so observed that it is a public health concern in the study area. Stunting is significantly influenced by mothers' education, household wealth and child age. Thus, nutritional intervention initiatives should focus on improving household food security and support maternal income generation as well as education. Further research work on the indifference between employed and unemployed mothers on under-five nutrition status is also recommended.

\section{ACKNOWLEDGEMENTS}

We extend our appreciation to the data collectors, supervisors and study participants for their cooperation. We also would like to thank Wolayta Sodo Health Department for providing the necessary information. The study was funded by, College of Public Health and Medical Science, Hawassa University.

DOI: http://dx.doi.org/10.4314/ejhs.v27i2.8 


\section{REFERENCES}

1. World Health Organization. World health statistics. Geneva; WHO report,: 2011.

2. World Health Organization. World health statistics. Geneva; WHO report, 2014.

3. Michael C. Human nutrition in the developing world. FAO; Food and nutrition series, 2012:125-30.

4. Central Statistical Agency [Ethiopia] and ORC Macro: Ethiopia demographic and health survey 2011. Addis Ababa; Ethiopia and Calverton, Maryland, USA: CSA, 2011.

5. World Bank. Repositioning Nutrition as Central to Development-A Strategy for Large Scale Action. Washington DC, USA, 2006.

6. Behrman JR, Hoddinitt J. An evaluation of the impact of progress on preschool child height. International food policy research institut, 2001.

7. Hlaing WW, Nath SD, Huffman FG. Assessing overweight and cardiovascular risks among college students. American Journal of Health Education, 2007;38 (2):83-90.

8. Bennett L. The role of women in income production and intra-household allocation of resources as a determinant of child nutrition and health. Food Nutr Bull, 1988;10(3):16-26.

9. Cogill B. Anthropometric indicators measurement guide. Food and nutrition technical assistance project: 2001.

10. United Nation. The World's Women 1997; trends and statistics. New York; UN: 1997.

11. Haddad L. Women's status, levels, determinants, consequences for malnutrition, interventions, and policy. Asian Development Review, 1999;17 (2): 96-131.

12. Vittinghoff E, Glidden DV, Shiboski SC, McCulloch CE. Regression methods in biostatistics: linear, logistic, survival, and repeated measures models (statistics for biology and health). Springer, 2005.

13. Kebede M, Kassahun A, Bikes D. Prevalence of malnutrition and associated factors among children aged 6-59 months at Hidabu Abote District, North Shewa, Oromia regional state. $J$ nutr disorders ther, 2013; 1(5):1-15. T1 http://dx.doi.org/10.4172/2161-0509.T1-001

14. Wolde T. Prevalence of underweight and its determinant factors of under two children in a rural area of Western Ethiopia. Food science and quality management: 2014;31(3):59.

15. Marie T, Garrett JL. Features of urban food and nutrition security and considerations for successful urban programming. Agricultural and development economics, 2004:1(2):24271.

16. Onis MC, Monteiro C, Clugston G. The worldwide magnitude of protein-energy malnutrition: an overview from the WHO global database on child growth. Bulletin of the WHO, 2012; 703-12.

17. Demissie S, Worku A. Magnitude and factors associated with malnutrition in children 6-59 months of age in pastoral community of Dollo Ado district, Somali region, Ethiopia. Science Journal of Public Health: 2013:1(4):175-83.

18. Manyike PC, Chinawa JM, Ubesie A, Obu HA, Odetunde OI, Chinawa AT. Prevalence of malnutrition among pre-school children in, Southeast Nigeria. Italian journal of pediatrics, 2014;40:75.

19. Ricci JA, Jerome NW, Sirageldin I, Moussa W, Galal O, Kirksey A. The significance of children's age in estimating the effect of maternal time use on children's well-being. Soc. Sci. Med, 1996;42(5):651-9. 